Nevşehir Bilim ve Teknoloji Dergisi (2018), 7(1) 24-31

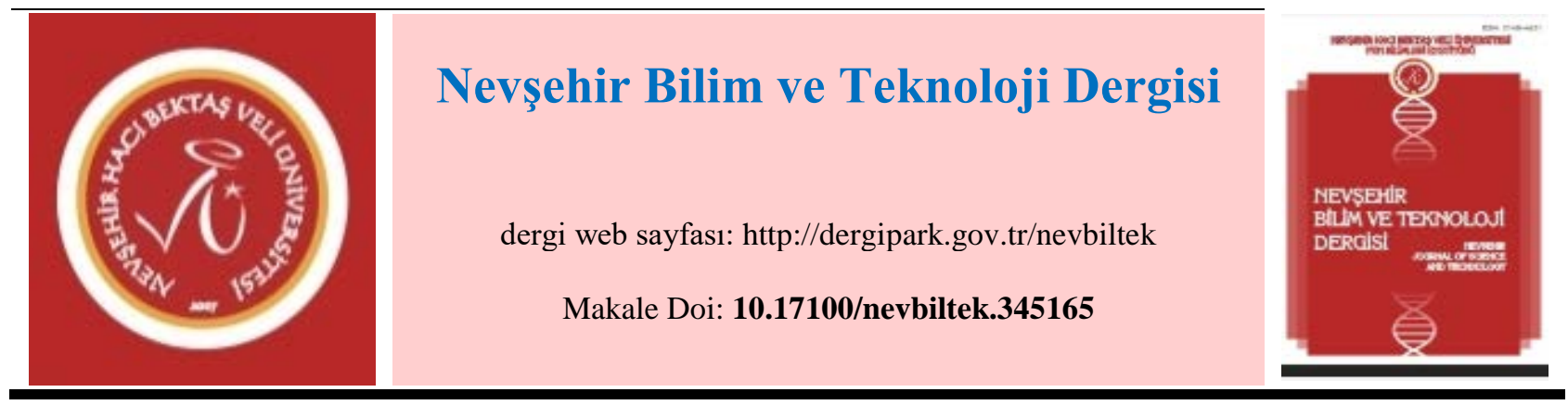

\title{
Vinclozolin’ in Galleria mellonella L. (Lepidoptera: Pyralidae)’ nın Erginleşme Süresi ve Eşey Oranı Üzerine Etkisi
}

\author{
Rahile ÖZTÜRK ${ }^{1}$, Yunus AKDOĞAN ${ }^{2}$ \\ ${ }^{1}$ Selçuk Üniversitesi, Fen Fakültesi, Biyoloji Bölümü, Konya \\ ${ }^{2}$ Selçuk Üniversitesi, Fen Fakültesi, İstatistik Bölümü, Konya
}

Öz

Bu çalışma, vinclozolinin, peteklere zarar veren ve ekonomik açıdan zararlı bir tür olan Galleria mellonella (Lepidoptera: Pyralidae)' nın bazı fizyolojik özelliklerine etkisini belirlemek amacıyla yapılmıştır. Deney grupları için, stok kültürlerden elde edilen yumurtalar, farklı dozlarda (25, 50, 75 ve 100 ppm) vinclozolin karıştırılmış besin içine bırakılmış ve yumurtadan çıkan larvaların bu besinle beslenmeleri sağlanmıştır. Sonrasında, bu larvaların erginleşme süreleri ile erginleşme sonucundaki eşey oranları belirlenmiştir. Deney sonuçlarına göre, uygulanan vinclozolin miktarının artmasının erginleşme süresini uzattı̆̆ı̆, erginleşme yüzdesini önemli ölçüde azalttığı ama meydana gelen erginlerin eşey oranlarında kontrol grubuna göre bir fark oluşturmadı̆̆ tespit edilmiştir.

Anahtar kelimeler: Erginleşme süresi, eşey oranı, Gallleria mellonella, vinclozolin

\section{Effect of Vinclozolin on Adult Emergence and Sex Ratio of Galleria mellonella L. (Lepidoptera: Pyralidae)}

\begin{abstract}
This study was aimed to determine the effect of vinclozolin on some physiological characteristics of Galleria mellonella (Lepidoptera: Pyralidae) which is an economically harmful species damaging in beekeeping. For experimental groups, the eggs obtained from stock were dropped into the mixed feed of vinclozolin at different doses (25, 50, 75 and 100 ppm) and had the larvae fed with this feed. Subsequently, the sex ratio of mated individuals and maturation time of these larvae were determined. According to the data, increase in the amount of applied vinclozolin prolonged the maturation period and reduced the percentage of maturation. But, when compared with the result of the control group, sex ratio of mature was determined to create no difference.
\end{abstract}

Keywords: Adult emergence, sex ratio, Galleria mellonella, vinclozolin 


\section{Giriş}

Gıdaların üretimi, saklanması ve tüketimi sırasında gıda maddelerine zarar veren mikroorganizma ve haşereleri uzaklaştırmak ya da yok etmek, ayrıca bitkilerin büyümesini düzenlemek amacıyla da kullanılabilen kimyasal ya da biyolojik ürünlere pestisit denir. Bu ilaçlar; böcek öldürücüler (insektisitler), yabani bitki öldürücüler (herbisitler), bakteriler üzerine ekili olan (bakterisitler), kemirgen öldürücüler (rodentisitler), mantar ve sporlar üzerine etki gösterenler (fungusitler, fumigantlar), nematotları öldüren (nematositler) ve kuşları öldüren (avisitler) olarak sınıflandırılmaktadır [1 ve 2].

İnsektisitler, bitki ya da hayvanlara zararlı olan organizmaların öldürülmesi veya kontrol edilmesi amacıyla, dünyada yaygın olan kimyasallardır. Bunların çeşidi, miktarı ve çevrede bulunma süresine bağlı olarak kalıntıları, yararlı böcekler gibi hedef olmayan türlerin çoğalma ve canlılık oranlarında azalışa neden olabilmektedir [3 ve 4].

Zararlılara karşı kullanılan insektisitler, böceklerde metabolizmada anormallikler, enzim aktivitelerinde farklılık, davranış bozuklukları, beslenme değişiklikleri, üreme ile parazitleme ve parazit çıkışı anormalliklerine sebep olmaktadırlar [5 ve 6]. İnsektisitlerin aksine, fungisitlerin akut toksisite yönünden önemli bir risklerinin olmamasına karşın, kronik toksisiteleri önemlidir [7].

Pestisitlerin kontrolsüz bir şekilde bilinçsiz olarak kullanılması, çevre kirliliğine ve hedef olmayan diğger canlılar üzerinde olumsuz etkilere yol açmaktadır. Kimyasal kirliliğe yol açan, çevrede ve besin maddelerinde uzun süre bozulmadan kalan ve besinlerle insanlara kadar ulaşabilen pestisitlerin alerjik, mutajenik ve teratojenik etkilerinin olduğu, yapılan bazı çalışmalarla gösterilmiştir [8 ve 9].

Asıl amaçları hastalık ve zararlıları yok etmek olan pestisitler, sürekli kullanıldıklarında hem ekolojik hem de ekonomik açıdan büyük sorunlara neden olmaktadır. Bu nedenle de pestisit uygulanacak türün biyoloji ve fizyolojisinin iyi bilinmesi ve doğaya zarar vermeden zararlı böceklerin kontrol altına alınması için uygun pestisit konsantrasyonunun belirlenmesi gerekmektedir.

Böceklerin gelişmesi, ömür uzunluğu ve çoğalmaları gibi özellikleri her ne kadar genetik ise de, çevre etkisi de oldukça önemlidir. Çevre, özellikle böceğin gelişme süresini, erginleşmesini, yumurta verimini ve eşey oranını etkileyen faktörlerden biridir.

Farklı böcek türlerini kimyasallara maruz bırakarak yapılan daha önceki çalışmalarda; ergin öncesi gelişim süresinin, eşey oranının, ergin ömür uzunluğunun, yumurta veriminin, puplaşma ve ölüm oranının, protein, lipid ve glikojen miktarlarının, malondialdehid (MDA) miktarının, bazı enzimlerin aktivitelerinin ve diapoz süresinin önemli ölçüde etkilendiği tespit edilmiştir [10- 16].

Bu çalışmada Galleria mellonella’ nın bazı fizyolojik özelliklerine etkisi incelenecek olan vinclozolin; canola, marul, kivi ve soğan gibi bazı sebze ve meyvelerin çeşitli hastalıklarını önlemek için kullanılan bir fungusittir. Vinclozolin ilk defa 1981 yılında Amerika’ da bir fungusit olarak kullanılmıştır. 1991 yılında vinclozolinin kalıntı miktarı, toksisitesi, çevreye etkisi ve ekolojik etkileri tanımlanmış ve 1995- 1996 yıllarında ekolojik toksisite çalışmaları yapılmıştır. 1997' de FQPA (Gıda Kalite Koruma Kanunu) altında kullanımına ilişkin tüm riskleri tekrar değerlendirilmiştir. Vinclozolin genel olarak ağız, deri ve solunum yoluyla düşük oranda canlıya geçmektedir. Vinclozolin ve türevlerinin toksik etkisi vinclozolinin anti- androjenik aktivitesine bağlıdır. Androjenler testesteron gibi erkeklerde temel steroit hormonlarıdır ve erkeklerin üreme sistemi ve ikincil eşey karakterlerinin işlevinde ve gelişiminde rol oynarlar. Ayrıca vinclozolin nöroendokrin sistemin fonksiyonunda ve gelişiminde de etkilidir [17].

Zararlı Lepidoptera türlerinin kültüre alınması, ekoloji ve fizyolojilerinin yanında bunların bazı metabolik olaylarının moleküler seviyede incelenmesine de imkan sağlar [18- 21]. Böylece yeni insektisitlerin, kullanılmalarından 
Nevşehir Bilim ve Teknoloji Dergisi (2018), 7(1) 24-31

önce laboratuvarda böcekdeki etkileri tespit edilmiş olmaktadır [22- 24]. Yüksek verim ve kısa hayat döngüsüne sahip olması, besin olarak koyu renkli bal peteği ve çeşitli yapay besinlerde iyi gelişmesi sebebiyle, G. mellonella konakparazitoid etkileşimi, biyolojik ve kimyasal mücadele çalışmaları için önemli bir deneysel model oluşturmaktadır [25].

$\mathrm{Bu}$ çalışmada, vinclozolin uygulamasının böceklerin fizyolojisine etkisi araştırılarak, daha sonraki uygulamalar açısından bu kimyasalın etki mekanizması tespit edilmiş olacaktır.

\section{Materyal ve Metot}

G. mellonella stok kültürü [26]' dan yararlanılarak hazırlanmış yarı sentetik besinde yetiştirilmiştir. Kavanozlara birkaç adet ergin koyularak $28 \pm 1^{\circ} \mathrm{C}, \% 60 \pm 5$ bağıl nem ve karanlıkta gelişmeye birakılmıştır. Deney grupları için, stok kültürlerden elde edilen yumurtalar, farklı oranlarda $(25,50,75$ ve 100 ppm) vinclozolin karıştırılmış besin içine bırakıldıktan sonra, meydana gelen larvaların bu besinle beslenmeleri sağlanmış ve vinclozolini bünyelerine almış olan son evre larvalar alınarak, böceğin bazı fizyolojik özelliklerini incelemek üzere çeşitli işlemlere tabi tutulmuşlardır. Kontrol grubu için de aynı işlemler, vinclozolin ilave edilmemiş besin ile beslenen larvalara uygulanmıştır. Hem kontrol grubu hem de deney grupları üç tekrarlı olarak çalışılmıştır.

Dört farklı dozda $(25,50,75$ ve 100 ppm) vinclozolin ile beslenmiş olan larvaların bulunduğu kavanozlardan bir kısmı (içlerinde eşit sayıda larva olacak şekilde), erginleşme süresinin tespiti ve oluşan erginlerin cinsiyetlerininin belirlenmesi için ayrılmıştır. Erginleşen bireylerin erginleşme süreleri ile cinsiyetleri not edilmiş ve besine karıştırılan vinclozolinin miktarına bağlı olarak oluşan değişimler, Tek Yönlü Varyans Analizi [27] ile karşılaştırılmıştır. Yüzde olarak hesaplanan değerler varyans analizlerinden önce arksinus karekökleri alınmak suretiyle [28] normalleştirilmiştir. Ortalamalar arası farklar Tukey gerçekten anlamlı farklılık (Tukey HSD) testleri ile belirlenmiştir. Değerlendirmelerde anlamlılık düzeyi $\alpha=0.05$ olarak esas alınmıştır.

\section{Bulgular}

Uygulamalar sonrasında çıkan bireylerin erginleşme süreleri ile eşey oranları Tablo 1 ve Tablo 2' de verilmiştir.

Tablo 1: Vinclozolin uygulaması sonrasında, erginleşme süresi (gün)

\begin{tabular}{ll}
\hline Vinclozolin miktarı (ppm) & Erginleşme süresi (gün) \\
\hline 0 & $28,59 \pm 0,41 \mathrm{~d}$ \\
25 & $37,40 \pm 0,39 \mathrm{bc}$ \\
50 & $38,87 \pm 0,53 \mathrm{bc}$ \\
75 & $42,20 \pm 0,30 \mathrm{a}$ \\
100 & $40,67 \pm 1,33 \mathrm{ab}$ \\
\hline
\end{tabular}

Değerler, her biri 10 larvadan oluşan 3 tekrarın ortalamasıdır.

Aynı sütunda aynı harfe sahip gruplar $(\mathrm{a}-\mathrm{b})$ birbirinden farksızdır $(\mathrm{P}>0,05)$.

(ANOVA) ikili karşılaştırma testlerinden Tukey Testi uygulanmıştır.

Vinclozolin uygulaması sonrasında, G. mellonella larvalarından ergin çıkış süresinin, tüm uygulama gruplarında vinclozolin miktarının artmasına bağlı olarak kontrol grubuna göre uzadığı görülmüştür. Sadece, 25 ve 50 ppm vinclozolin içeren besinle beslenen larvaların bulunduğu gruplardan çıkan erginlerin erginleşme süreleri arasında anlamlı bir fark tespit edilmemiştir. 
Nevşehir Bilim ve Teknoloji Dergisi (2018), 7(1) 24-31

Tablo 2: Vinclozolin uygulaması sonrasında, erginleşme yüzdesi ve eşey oranı (\%)

\begin{tabular}{lllc}
\hline Vinclozolin miktarı (ppm) & Toplam (\%) & \multicolumn{2}{c}{ Eșey oranı (\%) } \\
& & + & đ \\
\hline 0 & 90,00 & $55,00 \mathrm{a}$ & $45,00 \mathrm{a}$ \\
25 & 83,33 & $51,00 \mathrm{a}$ & $49,00 \mathrm{a}$ \\
50 & 76,67 & $52,00 \mathrm{a}$ & $48,00 \mathrm{a}$ \\
75 & 66,67 & $53,67 \mathrm{a}$ & $46,33 \mathrm{a}$ \\
100 & 20,00 & $77,67 \mathrm{a}$ & $22,33 \mathrm{a}$ \\
\hline
\end{tabular}

Değerler, her biri 10 larvadan oluşan 3 tekrarın ortalamasıdır.

Aynı sütunda aynı harfe sahip gruplar $(\mathrm{a}-\mathrm{b})$ birbirinden farksızdır $(\mathrm{P}>0,05)$.

(ANOVA) ikili karşılaştırma testlerinden Tukey Testi uygulanmıştır.

Deney sonuçlarına göre, uygulanan vinclozolin miktarının artışıyla beraber, toplam ergin çıkış yüzdesinde bir azalma gözlenmiştir. Ayrıca, uygulama gruplarındaki dişi ve erkek bireylerin çıkış yüzdeleri arasında anlamlı bir fark tespit edilememiştir.

\section{Tartışma ve Sonuç}

Kimyasal mücadele için kullanılan yeni insektisitlerin etkilerinin belirlenmesinde gelişme, yaşam uzunluğu ve yumurta verimi gibi parametrelerin yanında biyokimyasal ve fizyolojik değişimlerin de iyi bilinmesi gerekmektedir.

Kimyasal maddelerin subletal dozları, böceklerde genel olarak besin bulma ve besin alma, eşeysel haberleşmenin bozulması, parazitik bölgelerde ise özellikle konă̆ı tanıma, üremenin durması veya yavaşlaması, yumurtaların açılma gücünün yavaşlaması, yaşam süresinin kısalması gibi olayları etkilemektedir [29].

Arıcıllğın olduğu hemen hemen her yere yayılmış olan G. mellonella, bal arısının önemli zararlılarından birisidir. Bu türün larvaları; bal ve polenler ile beslenerek ciddi ekonomik kayıplara sebep olur. Sağlıklı kolonilerde güvenin zararı, işçi arılar tarafından kontrol edilmekte ise de; anasız ve zayıf kolonilerde, ciddi kayıplar meydana gelmektedir. En ağır kayıplar ise kış süresince depolanmış peteklerde görülmektedir [30].

Yapılan bir çalışmada, G. mellonella son evre larvalarına farklı dozlarda Cypermethtin uygulanmış ve konsantrasyon arttıkça larval gelişimin uzadığı tespit edilmiştir [31]. Biyolojik mücadelede bu türün parazitoitleri düşünüldüğünde, parazitoitin neslinin devamlılığı açısından (konağın gelişiminin uzaması ve pup evreye geç ulaşması) büyük tehlike yaratmaktadır. Farklı dozlarda Cypermethrin' in G. mellonella' nın puplaşması üzerine etkilerinin araştırıldığı bir diğer çalışmada, kimyasalın dozu arttıkça puplaşma süresinin geciktiği tespit edilmiştir [12]. Bizim deneylerimizin sonuçları, bu çalışmaların sonuçları ile benzerlik göstermektedir. Hayvanlar stres şartları ile karşılaştıkları zaman, mücadele süresince fazla miktarda enerjiye ihtiyaç duyarlar. Bu çalışmada vinclozolinin miktarına bağlı olarak gelişme zamanının gecikmesi, kimyasalın uygulanmasından dolayı meydana gelen stresin atlatılması için G. mellonella' nın enerji depolarında bir azalmanın meydana gelmiş olabileceği şeklinde açıklanabilir. Yine, bazı antimikrobiyal ajanların Pimpla turioellae larvalarının yaşama ve gelişmesine etkilerini belirlemek için yapılmış bir çalışmada, denenen ajanların etkilerinin çoğunlukla larva sonrası evrelerde ortaya çıktığını ve gelişmeyi olumsuz yönde etkilediği tespit edilmiştir [32].

Zararlı böceklerle mücadele için besinlere eklenen borik asit ve sodyum tetraborat gibi bor türevi kimyasalların yüksek miktarlarının gelişmeyi geciktirdiği, yaşam uzunluğunu artırdığı, yumurta verimini ve açılımını azalttığı, larva ve pup evresinde ölüm oranını yükselttiği tespit edilmiştir [33- 35]. Bizim çalışmamızda da benzer sonuçlar gözlenmiştir. Uygulanan vinclozolin miktarının artması, ergin çıkış süresini uzatmış, ergin çıkış oranını ise azaltmıştır. Bu sonuç, $G$. 
Nevşehir Bilim ve Teknoloji Dergisi (2018), 7(1) 24-31

mellonella mücadelesinde vinclozolin kullanılabilmesi anlamında bakıldığında (uygun dozlarda kullanıldığında) olumludur. Fakat G.mellonella’ nın biyolojik mücadelede parazitoitlerin konağı olarak laboratuvarda kitle üretimi için çoğaltılması anlamında bakıldığında ise gelişimi geciktirdiği için yeterli parazitoit üretememek adına olumsuz bir sonuçtur. Bundan dolayı vinclozolin, daha farklı konsantrasyon aralıklarında böceğin besinine karıştırılarak sonuçların fizyolojik anlamda değerlendirilmesi ve uygun dozun belirlenmesi gerekmektedir.

Günümüzde kimyasalların oluşturduğu bir okyanus içinde yaşamaktayız. Bilinçsiz uygulanan kimyasal mücadeleyle kanserojen, teratojen ve mutajen olan kimyasalların bu okyanustaki birikimi giderek artmaktadır [36]. Denetimsiz ve düzensiz kullanım, her geçen gün zararlının direnç kazanmasına sebep olarak, dozun zamanla daha da arttırılmasına neden olmaktadır [37]. Buna bağlı olarak hem çevre kirlenmesi hem de ekonomik kayıp artmaktadır.

Çeşitli özelliklerdeki kimyasalların böcekler üzerine uygulanması öldürücü olmasa bile, ağırlık, gelişme ve puplaşma oranı gibi özellikleri etkileyebileceği, yapılan bazı çalışmalarla gösterilmiştir [38- 40].

$\mathrm{Bu}$ çalışmada gıda sanayinde kullanılan vinclozolinin, metabolizma üzerine etkisinin belirlenmesinde G.mellonella model olarak kullanılmıştır. Böylece uygun vinclozolin konsantrasyon aralığı belirlenerek, en az seviyede pestisit kullanımı için gereken miktar tespit edilmeye çalışılmıştır. Bu çalışmadan elde edilen veriler kullanılarak kimyasal mücadelede kullanılan diğer pestisitlerin canlı metabolizmasına etkisinin araştırılması için sonraki çalışmalara katkı sağlaması düşünülmüştür. Çünkü büyük balmumu güvesine karşı kullanılan kimyasalların çoğu ürünlerde kalıntı bıraktığı için, pazar şansını düşürmekte ya da yok etmektedir. Bu açıdan günümüzde, kullanılan kimyasal maddelerin kalıntı durumu ve uygulanabilme kolaylığı göz önünde bulundurularak yeni arayışlara yönelmek gerektiği kaçınılmaz olmuştur. Dolayısıyla zararlı böceklere karşı kullanılacak kimyasalın çeşidinin, dozunun ve zamanlamasının seçimi, zararlının populasyon yoğunluğunu baskılamada önemli bir konu olarak karşımıza çıkmaktadır.

Ülkemiz ekonomisine önemli katkı sağlayan kovan ürünlerinin zararlısı üzerinde yapılan bu çalışma, kovan zararlısı böceklerin zararlı etkilerini ortadan kaldırmaya yönelik girişimler için yönlendirici olacaktır.

\section{Teșekkür}

Bu çalışma Selçuk Üniversitesi tarafından desteklenmiştir (BAP Proje No: 11401118). Projenin yürütülmesinde maddi destek sağlayan Selçuk Üniversitesi Bilimsel Araştırmalar Koordinatörlüğü’ ne teşekkürlerimizi sunarız.

\section{Kaynaklar}

[1] Öncüer C., “Tarımsal Zararlılarla Savaş Yöntemleri ve İlaçları” Genişletilmiş 5. Baskı, Adnan Menderes Üniversitesi Yayınları, No:19, 424s, Aydın, 2004

[2] Bostancı E.B., Teke Z., Ulaş M., Akoğlu M., "Karbamatlı insektisitle zehirlenmiş bir vericiden alınan karaciğerin başarıyla nakledilmesi: Akut intoksikasyon organ alımına engel midir?’ Ulusal Cerrahi Dergisi, 27(2): 115- 119, 2011

[3] Vural N., “Toksikoloji” Ankara Üniversitesi, Eczacılık Fakültesi Yayınlarl, No: 73, 334 s, Ankara, 2005

[4] Miller A.L., Tindall K., Leonard B.R., “Bioassays for monitoring insecticide resistance” J. Vis. Exp., (46), e2129, doi: 10.3791/2129, 2010

[5] Haynes K.F., “Sublethal effects of neurotoxic insecticides on insect behvior” Ann. Rev. Entomol., (33)149-168, 1988

[6] Dursun O., “DDVP’ nin (Dichlorvos) Subletal Dozlarının Galleria mellonella L. 'nın Protein, Lipit ve Karbohidrat Düzeyine Etkileri” Çukurova Üniversitesi, Fen Bilimleri Enstitüsü, Yüksek Lisans tezi, Adana, 2009

[7] Anonim, “Regulating Pesticides in Food” The Delaney Paradox National Academy Pres., 272 pp, Washington DC, 
Nevşehir Bilim ve Teknoloji Dergisi (2018), 7(1) 24-31

[8] Vural N., “Toksikoloji” Ankara Üniversitesi, Eczacılık Fakültesi Yayınları, No:56, 416 s, Ankara, 1984

[9] Asal S., "Bazı pestisitlerin mutajenik etkileri üzerine araştırmalar” Doğa Bilim Derg., D-2, 9:1, 72-78, 1985

[10] Erdoğan P., Toros S., “Melia azedarach L. (Meliaceae) ekstraktlarının Patates böceği [Leptinotarsa decemlineata Say (Col.: Chrysomelidae)] larvalarının gelişimi üzerine etkisi” Bitki Koruma Bülteni, 45(1-4): 99-118, ISSN 0406-3597, 2005

[11] Uçkan F., Tüven A., Er A., Ergin E., "Effects of giberellic acid on biological Parameters of the larval endoparasitoid Apanteles galleriae (Hymenoptera: Braconidae)” Entomol Ann Soc Am., 101(3): 593-597, 2008

[12] Sak O., Uçkan F., “Cypermethrinin Galleria mellonella L. (Lepidoptera: Pyralidae)’nın puplaşma ve ölüm oranlarına etkisi” Uludă̆ Arıculk Dergisi, 9(3): 88-96, 2009

[13] Şahin V., “Borik Asitin Laktoz ile Birlikte Galleria mellonella L. (Lepidoptera: Pyralidae)’ nın Bazı Biyolojik ve Biyokimyasal Parametrelerine Etkisi” Zonguldak Karaelmas Üniversitesi, Fen Bilimleri Enstitüsü, Yüksek Lisans tezi, Zonguldak, 2010

[14] Sezer B., Özalp P., “Azadirachtinin Galleria mellonella larvalarında total glikojen miktarına etkisi” Ekoloji, 20, 81, 67-72, 2011

[15] Rashid M., Wagchoure E.S., Mohsin A.U., Raja S., Sarwar G., “Control of ectoparasitic mite Varroa destructor in honeybee (Apis mellifera L.) colonies by using different concentrations of oxalic acid” The Journal of Animal \& Plant Sciences, 22(1): 72-76, ISSN: 1018-7081, 2012

[16] Bozdoğan H., Bahadıroğlu C., "Çeşitli insektisit gruplarının Chrysopidae Schneider 1851 familyasına ait bazı böcekler üzerindeki etkisi” BEÜ Fen Bilimleri Dergisi, 3(2): 192-198, 2014

[17] EPA, “Preventation, Pesticides and Toxic Substances Guidelines (7508C)” EPA, 738-F-021, October, 2000

[18] Mantado C.A., Diehl-Jones W.L., Moore S.J., Downer R.G.H., “The effects of eicosanoids biosynthesisinhibitors on prophenoloxidase activation, phagosytosis and cell spreading in Galleria mellonella” J. Insect Physiol., Vol. 43(1), pp. 1-8, 1997

[19] Pohlon E., Baldwin I.T., “Artificial dies 'capture' the dynamics of jasmonate induced defenses in plants” Entomologia Experimentalis et Applicata, 100:1, 127-130, 2001

[20] Büyükgüzel K., Tunaz H., Putnam S.M., Standey D.W., "Prostaglandin biosynthesis by midgut tissue isolated from the tobacco hornworm, Manduca sexta” Insect Biochem. Molec., Vol. 32, no 4, pp. 435-443, 2002

[21] Tunaz H., Park Y., Büyükgüzel K., Bedick J.C., Nor Aliza A.R., Standey D.W., "Eicosanoids in insect immunity: bacterial infection stimulates hemocytic phospholipase A2 activityin tobacco hornworms” Arch. Insect Biochem., Vol.52(1), pp.1-6, 2003

[22] Wiedenmann R.N., Smith J.W., Darnell P.O., "Laboratory rearing and biology of the parasite Cotesia flavipes (Hymenoptera: Braconidae) using Diatraea saccharalis (Lepidoptera: Pyralidae) as a host” Environ. Entomol., Vol. 21, 1160-1167, 1992

[23] Gupta P., Sloan A., Dillard C.R., Frekovich S.M., "Parasitism of factitious host, Galleria mellonella (Lepidoptera: Pyralidae) by an endoparasitoid: ovoposition and emergence of Microplitis croceipes (Hymenoptera: Braconidae)” Fla. Entomol., Vol. 79(2), 221-229, 1996

[24] Büyükgüzel K., "Positive effects of some gyrase inhibitors on survival and development of Pimpla turionellae L. (Hymenoptera: Ichneumonidae) larvae reared on an artificial diet” J. Econ. Entomol., 94: 21-26, 2001

[25] Jarosz J., “Simplified technique for prepearing germ- free specimens of greater wax moth (Lepidoptera: Pyralidae) larvae” J. Econ. Entomol., Vol. 82, 1478-1481, 1989

[26] Bronskill J., “A cage to simplify the rearing of the greater wax moth, Galleria mellonella (Pyralidae)” J. Lep.Soc., Vol. 15, No 2, 102-104, 1961 
Nevşehir Bilim ve Teknoloji Dergisi (2018), 7(1) 24-31

[27] SPSS Inc, “SPSS 10.0 Statistics” SPSS, Chicago, IL, 1999

[28] Sokal R.R., Rohlf F.J., “Biometry” Freeman, San Francisco, CA, 1995

[29] Şahin A., "Farklı Dozlarda Konağa Verilen Cyperpethrinin Parazitoit Apanteles galleriae Wilkson (Hymenoptera: Braconidae) Biyolojisine Etkileri” Balıkesir Üniversitesi, Fen Bilimleri Enstitüsü, Yüksek Lisans tezi, Balıkesir, 2004

[30] Tutkun E., Boşgelmez A., "Bal Arısı Zararlıları ve Hastalıkları Teşhis ve Tedavi Yöntemleri” Bizim Büro Basımevi, Ankara, 2003

[31] Sak O., “Cyperpethrinin Pimpla turionellae L. (Hym.; Ichneumonidae)’ nın, Toplam Protein, Lipit ve Karbohidrat Miktarı ile Hemositlerine Etkisi” Balıkesir Üniversitesi, Fen Bilimleri Enstitüsü, Doktora tezi, Balıkesir, 2004

[32] Büyükgüzel K., Yazgan Ş., "Effect of antimicrobial agents on the survival and development larvae of Pimpla turionellae L. (Hymenoptera: Ichneumonidae) reared on an artificial diet” Turk J Zool, 26, 111-119, 2002

[33] Zurek L., Gore J.C., Stringham S.M., Watson D.W., Waldvogel M.G., Schal C., "Boric acid dust as a component of an integrated cockroach management program in confined swine production” J. Econ. Entomol., 96, 1362-1366, 2003

[34] Xue R.D., Bernard D.R., “Boric acid bait kils adult mosquitoes (Diptera: Culicidae)” J Econ Entomol., 96: 15591562, 2003

[35] Gore J.C., Zurek L., Santangelo R.G., Stringham S.M., Watson D.W., Schal C., "Water solutions of boric acid and sugar for management of German cockroach populations in livestock production systems” J. Econ. Entomol., 97, 715-720, 2004

[36] Shukla Y., Yadav A., Arora A., “Carcinogenic and cocarcinogenic potential of cypermethrin on mouse skin” Cancer Letters, 182: 33-41, 2002

[37] Soderlund D.M., Knipple D.C., "Knockdown resistance to DDT and pyrethroids in the house fly (Diptera: Muscidae): from genetic trait to molecular mechanism” Entomological Society of America, Vol. 92, No. 6, 909-915, 1999

[38] Takada Y., Kawamura S., Tanaka T., "Effects of various insecticides on the development of the egg parasitoid Trichogramma dendrolimi (Hymenoptera: Trichogrammatidae)” J. Econ. Entomol., 94(6): 1340-1343, 2001

[39] Tomberlin J.K., Sheppard D.C., Joyce J.A., “Susceptibility of black soldier fly (Diptera: Stratiomyidae) larvae and adults to four insecticides” J. Econ. Entomol., 95(3): 598-602, 2002

[40] Ergin E., Er A., Uçkan F., Rivers D.B., "Effect of cypermethrin exposed hosts on eggadult development time, number of offspring, sex ratio, longevity, and size of Apanteles galleriae Wilkinson (Hymenoptera: Braconidae)” Belg. J. Zool., 137(1): 27-31, 2007 


\section{Nevşehir Bilim ve Teknoloji Dergisi (2018), 7(1) 24-31}

\section{Extended Abstract}

Introduction: Today we live in an ocean of chemistry. With unconscious chemical struggle, the accumulation of carcinogenic, teratogenic and mutagenic chemicals in this ocean is steadily increasing. Uncontrolled and irregular use causes the dose to increase even more over time, causing the harmful resistance to gain day by day. As a result, both environmental pollution and economic loss are increasing. It has been shown in some studies that the application of chemicals in various properties to insects may affect properties such as weight, development and pupation rate, even if not fatal. Galleria mellonella host- parasitoid interaction is an important experimental model for biological and chemical combat studies because it has a high yield and a short life cycle, and is well- developed in nutrient dark honey pellets and various artificial nutrients. In this study, the effect of vinclozolin application on the physiology of insects will be investigated and the mechanism of action of this chemical will be determined in terms of subsequent applications.

Method: For experimental groups, the eggs obtained from stock were dropped into the mixed feed of vinclozolin at different doses (25, 50, 75 and 100 ppm) and had the larvae fed with this feed. Subsequently, the sex ratio of mated individuals and maturation time of these larvae were determined.

Results and Discussion: According to the data, increase in the amount of applied vinclozolin prolonged the maturation period and reduced the percentage of maturation. But, when compared with the result of the control group, sex ratio of mature was determined to create no difference.

In determining the effects of new insecticides used for chemical struggle, biochemical and physiological changes as well as parameters such as development, life span and egg yield should be well known. The subletal doses of chemical substances affect the incidence of nutrient finding and food intake in insects, sexual communication disorder in parasitic areas, especially mosquito recognition, slowing or stopping of uremia, slowing of egg opening, and shortening of life span.

In this study, G. mellonella model was used to determine the effect of vinclozolin, which is used in food industry, on metabolism. Thus, by determining the appropriate vinclozolin concentration range, it was attempted to determine the amount required for pesticide use at the minimum level. In order to investigate the effect of the data obtained from this study on the live metabolism of other pesticides used in chemical struggle, contribution to subsequent studies has been considered. Because most of the chemicals used against the great waxy gut leave a residue on the products, reducing or eliminating the market's chances. From this point of view, it is inevitable that we should aim for new quests considering the residual state of the used chemical substances and the applicability. Therefore, the selection of the type, timing and dosage of the chemical to be used against harmful insects is an important issue in suppressing the population density of the harmful insects. This work on the pest of hive products that make a significant contribution to our national economy will be a guide for initiatives to remove the harmful effects of hive pest insects. 